\title{
Leaders
}

\section{The Intercollegiate Academic Board of Sport and Exercise Medicine}

The medical royal colleges are under intense scrutiny by the government. The media are enjoying a feeding frenzy on the wayward actions of the few, while the competence of the committed but ordinary majority and the excellence of the leaders in our profession are derided or discounted. The public are seeking compensation for the hazards of a modern lifestyle as well as perceived lapses or misunderstandings following our profession's stumbling attempts to seek a measured response to all ailments. The lawyers are studying our textbooks.

Medicine is in serious danger of losing its professional unity as well as its self confidence, dignity, and drive to innovate.

In spite of these distractions, the Academy of Medical Royal Colleges has acknowledged that doctors practising sport and exercise medicine need to define and meet recognised standards of education, training, and clinical competence to protect the public as well as the profession. To this end, the Intercollegiate Academic Board of Sport and Exercise Medicine has been established to function in a role equivalent to a specialist advisory committee on behalf of, and reporting to, its parent colleges and faculties who are full members of the Academy. In addition, the Board has a category of associate membership for appropriate bodies who are not full members of the Academy (table 1).

The Intercollegiate Academic Board of Sport and Exercise Medicine has an agreed constitution, business plan, and memorandum of understanding which requires the Board to report its progress to the Academy in July 2000. The Board has agreed that its initial priority is to build upon the existing Scottish Medical Royal Colleges Diploma in Sport and Exercise Medicine for Great Britain and Ireland. The Diploma will assess basic specialty training standards for the "touchline doctor" as well as doctors in, for example, primary care or orthopaedics with a subspecialty interest. The Board hopes to introduce the new Diploma examination in April 1999. The examination will follow the same basic format of the present Scottish examination with a multiple choice paper, a theoretical paper of short essay questions, an oral examination and a practical examination testing core skills, clinical examination, and scenario tests. It is proposed that candidates would only proceed to the oral and practical components

Table 1 Members of the Intercollegiate Academic Board of Sport and Exercise Medicine

Royal College of Surgeons of Edinburgh

Royal College of Physicians of Edinburgh

Royal College of Physicians and Surgeons of Glasgow

Royal College of Surgeons of England

Royal College of Physicians of London

Royal College of Surgeons in Ireland

Royal College of General Practitioners

Royal College of Pathologists

Royal College of Radiologists

Royal College of Paediatrics and Child Health

Faculty of Occupational Medicine

Faculty of Public Health

Faculty of Dental Surgery at the Royal College of Surgeons of England

Faculty of Accident and Emergency Medicine

Medical Services of the Armed Forces of the examination if they had achieved a satisfactory mark in the two written papers.

The Board plans to develop a higher specialty training programme in sport and exercise medicine which will meet the standards of the Specialist Training Authority and result in successful trainees being awarded a Certificate of Completion of Specialist Training (CCST). The Board will develop the curriculum, syllabus, regulations, appraisal, and assessment procedures which will act as the basis for a four year Higher Specialty Training Programme in Sport and Exercise Medicine. This will take time but we plan to have the basis of the programme established by July 2000.

The Board will also seek approval for a flexible training year in sport and exercise medicine for trainees in a wide range of higher specialty training programmes - for example, rehabilitation medicine, rheumatology, and orthopaedic surgery. This will require close cooperation with the specialty advisory committees of these specialties as well as identifying and approving suitable flexible training programmes. It may be feasible to incorporate aspects of the present university based taught MSc programmes in sport and exercise medicine within this concept of a flexible training year.

The Board has no direct responsibility for the development of sport and exercise medicine as a part of the undergraduate curriculum. The Board believes that there is tremendous interest among medical students in sport and exercise medicine. The Board hopes that the development of basic and higher specialty training programmes in sport and exercise medicine will encourage universities to recognise the value of teaching exercise pathophysiology to undergraduates as well as encouraging opportunities in the form of special study modules and electives in sport and exercise medicine.

The format of the Board demonstrates genuine and innovative intercollegiate development, which will give our profession an opportunity to show an increasingly cynical public and government that the colleges and faculties are interested in improving the fitness of the nation as well as caring for exercisers and athletes. The success of the Board will be measured by the development of a cohort of doctors for tomorrow's world with basic and higher specialty training in sport and exercise medicine. This ambition can only be achieved if those doctors already committed to sport and exercise medicine continue to participate in educational and training developments and strengthen their own professionalism by including sport and exercise medicine in their continuing medical education and professional development programmes. The Board would encourage all doctors at present committed to sport and exercise medicine to join a relevant specialty association such as the British Association of Sport and Medicine (BASM) and keep up to speed in developments in the specialty by actively participating in the regional meetings, national courses, and congress of BASM as well as by reading the excellent British fournal of Sports Medicine.

The Board must make every effort to ensure that there are career opportunities and funding for sport and exercise 
medicine within the NHS - in primary care, community medicine, and in hospitals with sport and exercise medicine clinics as well as links to centres of excellence for the management of specialist problems. Accordingly the Board plans to enter discussions with the NHS Management Executive. In addition, the governing bodies of sport are increasingly expecting and are prepared to pay highly qualified and experienced doctors to advise them on all aspects of their sport as well as providing a clinical service for participants. Development of the United Kingdom Sports Institute and its regional distributed network throughout Scotland, England, Northern Ireland, and Wales will also provide career opportunities and employment for doctors with basic and higher specialty training as well as experience in sport and exercise medicine. All these developments have implications for "terms and conditions of service" which will be drawn to the attention of the British Medical Association.

In the past, sports medicine was described as elitist. The
Intercollegiate Academic Board of Sport and Exercise Medicine believes that the development of this subspecialty interest will help improve the fitness of the nation, the management of soft tissue injuries, and the care offered to individuals participating in exercise for the benefit of their health as well as competitive athletes. The Board recognises that these ambitions can only be achieved with the support of a wide range of educational and administrative bodies committed to sport and exercise medicine and hopes to liaise closely with them while developing its plans for the future.

The Intercollegiate Board can be contacted by writing to its administrative base which is at the Royal College of Surgeons of Edinburgh, Nicolson Street, Edinburgh EH8 9DW.

DONALD A D MACLEOD Chairman, Intercollegiate Academic Board of Sport and Exercise Medicine

\section{"Boosting" performance in disability sport}

There is no less contentious issue in elite sport than doping to enhance performance. Athletes are always looking to find the edge over opponents by fair means, or by foul in some cases. Potentially hazardous risks to health through doping are taken in the pursuit of sporting excellence. The increasing profile of disability sport and its potential rewards combined with the frailty of human nature has led some athletes with disabilities to seek improved performance through the administration of banned substances. There is, however, a doping method unique to disability sport, which is termed "boosting". Boosting is the intentional induction of autonomic dysreflexia to enhance performance and was deemed a banned method by the International Paralympic Committee (IPC) in 1994. But how and why did this practice come about?

The tetraplegic athlete has limited potential for improvements in cardiac output and maximal oxygen uptake for several reasons. Firstly, the loss of sympathetic cardiac innervation results in a maximum heart rate of between 110 and 130 beats per minute determined by intrinsic sinoatrial activity. ${ }^{1}$ The restricted heart rate reserve and reduced stroke volume are further compounded by a loss of catecholamine response to exercise and by the absence of the muscular venous pump in the lower limbs. These are limiting factors on performance that some tetraplegic athletes believe can be partly compensated for by the induction of the dysreflexic state.

Autonomic dysreflexia is a clinical phenomenon unique to patients with spinal cord injury above the major sympathetic outflow tract. ${ }^{2}$ The lesion is most commonly at or above the T6 level and therefore occurs in high paraplegic and more commonly in tetraplegic subjects. A nociceptive stimulus below the level of the spinal cord injury may initiate reflex sympathetic activity. Absence of higher control over reflex sympathetic activity due to cord injury is the main problem, but additional factors such as supersensitivity of receptors have also been implicated. ${ }^{3}$ Systemic hypertension occurs which is not controlled by feedback of the parasympathetic system, but flushing above the level of the lesion, vascular headache, and nasal congestion occur. Autonomic dysreflexia has been regarded as a medical emergency because of the substantial rises in blood pressure that can occur. ${ }^{4}$ Complications include seizures, ${ }^{5}$ cerebral haemorrhage, ${ }^{6}$ cardiac arrhythmia, ${ }^{7}$ and death ${ }^{6}$ Perhaps not surprisingly then the IPC medical committee deemed boosting to be a banned method in an attempt to avoid a fatality in competitive sport.

But why should athletes intentionally induce such a potentially life-threatening state? During training and competition some tetraplegic athletes had noticed that the dysreflexic state actually reduced the rating of perceived exertion for pushing, and faster top speeds were achieved. Although initially the phenomenon was occurring spontaneously, it was found that the condition could be induced by practices including clamping of the urinary catheter to produce bladder distension, excessive tightening of the leg straps, twisting and/or sitting on the scrotum. Athletes felt that in this way they could control the boosted state to command. A study of eight athletes using this technique during maximal treadmill tests and during simulated races confirmed significant performance enhancement, with the most striking change being a $9.7 \%$ improvement in race performance time. ${ }^{8}$ This would be about equivalent to reducing the able bodied marathon record by 12 minutes! In the boosted state at rest there was a lower heart rate, and during exercise subjects were able to achieve levels in excess of the normal maximum. Significant rises in noradrenaline levels were seen $(7.1 v 2.35 \mathrm{nmol} / 1$ in the unboosted state), but no change in adrenaline levels occurred. Athletes felt that they were only getting access to a catecholamine response and heart rate reserve that they could normally achieve in exercise if uninjured. However, significant rises in blood pressure were observed during the study, and the reported ability to control the response was found to be fallacious. There are no reported incidents of adverse events occurring during induced autonomic dysreflexia during exercise. Possibly the cardiovascular fitness of the athlete has a protective effect when compared with the deconditioned patient in a spinal injury unit but the numbers taking part in elite disability sport with this level of lesion are relatively small.

The IPC, having deemed boosting to be a banned method of doping, have a real practical problem with enforcement. Although the concern is for the safety of athletes, there are comparisons with growth hormone abuseunless you catch the athlete in the act, how do you detect 
it? Firstly, autonomic dysreflexia occurs spontaneously in tetraplegics and so to enforce this ban there has to be a method of not only detecting an athlete in a dysreflexic state but also proving that the state was intentionally induced. The first is not easy during a race. You cannot "pit stop" athletes for blood pressure checks. Blood pressure measurements were made in the call up room at the Atlanta Paralympics, and the potential threat was to withdraw athletes with abnormally high readings. The "normal value" for blood pressure in a call up room before a Paralympic final is difficult to predict, but I suspect the IPC may be open to litigation if they withdrew an athlete on these grounds. The importance of education of athletes and dialogue with athletes is surely the way forward in preventing a potential disaster, and this task has yet to be addressed by the IPC. For the sports physician working with athletes with this disability it is important to be aware of this condition, whether intentionally induced or not. The immediate management is to remove the nociceptive stimulus where possible and to administer sublingual nifedipine to reduce the blood pressure.

\section{Time to get tough on doping!}

1998 might aptly be named "the year of doping". To reiterate, doping became one of the biggest issues in international sports during this past year when the Tour de France was hit by the worst drug scandal in its history. In the middle of the scandal the president of the International Olympic Committee (IOC), Juan Antonio Samaranch, ignited a controversy when he suggested in a Spanish newspaper interview that some "harmless" performance enhancing drugs should be legalised. He justified his comment on the basis that only drugs which damage health should be banned. Last year we also endured an Italian "fiasco", with authorities investigating the national Olympic committee testing laboratory, and the continuation of criminal proceedings against former German Democratic Republic sports officials. Investigations have made clear that the former German Democratic Republic systematically doped its athletes, achieving the highest level of performance and easily avoiding detection. ${ }^{1}$

Oddly enough, the events of 1998 may turn out to be as important for the cause of fair and safe competition as the doping related deaths in the 1960s and the Ben Johnson case in $1988,{ }^{2}$ because the ensuing negative media exposure and threat of further government intervention have prompted the IOC to reconsider current measures to combat doping and renew discussions about the list of banned substances and methods to detect their use.

The proposals include a single Olympic medical code adopted by all the organisations belonging to the Olympic movement. In plain words, federations which don't fully comply with the regulations could be dropped from the Olympic Games. The regulations call for a minimum two year suspension and heavy fines for athletes found guilty of taking steroids and other performance enhancing substances, the creation of an independent anti-doping agency to coordinate expanded testing outside competitions, and the consolidation of scientific and technical standards and procedures for analyses and equipment in accordance with ISO quality standards.

The experience from Norway suggests that intensive, unannounced, out-of-competition testing with strict legal follow up-including, in the case of anabolic agents, a
A D J WEBBORN

The Sussex Centre for Sport and Exercise Medicine

Honorary Medical Officer, The British Paralympic Association

Hoffman MD Cardiorespiratory fitness and training in quadriplegics and paraplegics. Sports Med 1986;3:312-30.

2 Lee BY, Karmakar MG, Herz BL, et al. Autonomic dysreflexia revisited. $\mathcal{F}$ Spinal Cord Med 1995;18:75-87.

3 Arnold JM, Feng QP, Delaney GA, et al. Autonomic dysreflexia in tetraplegic patients: evidence for alpha-adrenoceptor hyper-responsiveness. Clin Auton Res 1995;5:267-70.

4 Naftchi NE, Richardson JS. Autonomic dysreflexia: pharmacological management of hypertensive crises in spinal cord injured patients. F Spinal Cord Med 1997;20:355-60.

5 Yarkony GM, Katz RT, Wu YC. Seizures secondary to autonomic dysreflexia. Arch Phys Med Rehabil 1986;67:834-5.

6 Eltorai I, Kim R, Vulpe M, et al. Fatal cerebral hemorrhage due to autonomic dysreflexia in a tetraplegic patient: case report and review. Paraplegia 1992;30:355-60.

7 Forrest GP. Atrial fibrillation associated with autonomic dysreflexia in patients with tetraplegia. Arch Phys Med Rehabil 1991;72:592-4.

8 Burnham R, Wheeler G, Bhambhani Y, et al. Intentional induction of autonomic dysreflexia among quadriplegic athletes for performance enhancment: efficacy, safety and mechanism of action. Clinical fournal of Sports Medicine 1994;4:1-10.

minimum two year suspension for a first major offence and suspension for life for a second offence-is an effective deterrent. In a recent study we examined the results from doping controls conducted by the Norwegian Confederation of Sport. ${ }^{3}$ We noted a significant decrease in the percentage of positive samples, from $2.4 \%$ in $1984-89$ to $1.0 \%$ in 1990-95 as testing frequency was gradually increased. But even if the data show that increased testing is associated with a decrease in the percentage of positive samples, the limitations in the ability to detect doping must be acknowledged, and possibly, athletes have switched to presently undetectable substances such as growth hormone and erythropoietin (rhEPO).

We applaud the proposals for an intensified international out-of-competition testing programme. However, for the new campaign to succeed, every effort must be made to improve the sensitivity and specificity of detection methods. The establishment of an international programme to fund and coordinate research in doping control is essential. A good case in point is the effort to detect the use of recombinant erythropoietin. Wide and coworkers from Sweden proposed a promising method for distinguishing between endogenous and recombinant EPO in $1990,{ }^{4}$ and later provided data that it may be effective in detecting rhEPO misuse. ${ }^{5}$ An adequately funded and concerted international research effort would probably have been able to explore the merits of the Wide method by now, and might have prevented the scandal in the Tour de France this past summer.

Even with intensified research into more sensitive detection methods, pharmaceutical research will continue to produce new compounds to improve health, but these will also have the potential for misuse by athletes because of their suspected or proved effect on various aspects of training or performance. Unfortunately, this provides a situation where there will always be a time delay between the introduction of a new "doping agent" and the advancement of appropriate detection methods. A potential solution to this dilemma would be the collection of a "third sample" ("C") in doping control-that is, split the sample (urine or blood) into three aliquots instead of the present 
two. If the A sample is negative, the $\mathrm{B}$ sample (for new screening) and the $\mathrm{C}$ sample (for confirmation analysis) may be stored until new detection methods have been developed. Although we acknowledge that the proposal has some ethical, legal, and practical considerations which need to be considered, the benefit of the $\mathrm{C}$ sample is that it greatly increases the level of uncertainty of detection in the mind of the unethical coach or athlete and thus increases the level of deterrence.

The need to establish a rational set of criteria to determine which substances and methods should be included on the banned list is another issue that needs to be addressed. But there are many reasons to reject the idea of "safe doping". Firstly, there is ample evidence that the doping substances and methods on the present list would carry significant health risks, even if monitoring by medical personnel were allowed. ${ }^{16}$ Secondly, supplying drugs to people without medical problems is contrary to the very basis of the medical profession. Thirdly, athletes are important role models for young and old, and placing them in the position of having to use drugs to compete does not produce laudable role models. Finally, we simply refuse to accept the idea that drug taking is a necessary price to pay to reach the highest levels of sport.

The proposed strategy is, in our opinion, sound. The IOC is the only international sports authority with the power and resources to say: "If your athletes, your coaches, your sport, and your nation want to be part of the Olympic movement, you must comply with certain international standards!" The short term price that may have to be paid is the negative publicity associated with a high number of positive cases. But if this expense is not met, sport will be destroyed from within. Let us hope that "the year of doping" has provided enough of a momentum for the current efforts to be successful, so that we may applaud our children and our grandchildren in their striving for excellence in sport in an environment of safety and fair play.

R BAHR J STRAY-GUNDERSEN

University of Sport and Physical Education

PO Box 4014 Ullevaal Stadion

0806 Oslo, Norway athletes: a secret program of the German Democratic Republic government. Clin Chem 1997;43:1262-79.

2 Dubin CL. Commission of inquiry into the use of drugs and banned practice intended to increase athletic performance. Ottawa, Canada: Canadian Government Publishing Centre, 1990.

3 Bahr R, Tjørnhom M. Prevalence of doping in sports-doping control in Norway 1977-1995. Clin f Sports Med 1998;8:32-7.

4 Wide L, Bengtsson C. Molecular charge heterogeneity of human serum erythropoietin. Br f Haematol 1990;76:121-7.

5 Wide L, Bengtsson C, Berglund B, et al. Detection in blood and urine of recombinant erythropoietin administered to healthy men. Med Sci Sports

Exerc 1995;27:1569-76.

6 Reilly T, Orme M, eds. The clinical pharmacology of sport and exercise. Amsterdam, The Netherlands: Elsevier, 1997.

\section{Women's greatest handicaps: sex, medicine, and men}

Women are rarely allowed to compete head to head with men. Billie Jean King's gimmicky tennis match against self proclaimed chauvinist pig Bobby Riggs in 1973 was an inconclusive reminder of the absurdity of mixed competition. Yet, is the idea so ridiculous? Few doubt that in many sports women would be hard pressed to hold their own; yet in the United States, there have been female professionals in such male dominated sports as ice hockey and boxing, and, more recently, baseball player Ila Borders became the first woman to pitch in a men's professional league.

In other lower profile sports, women have been challenging the seemingly unchallengable notion that men are-and will forever be - superior. Tagla Laroupe's 2:20.47 marathon record may be some way behind Roberto Da Costa's 2:09.07, but women's records were only kept from 1964 . Since then, women's best times have improved by an average yearly increment of over 2 minutes 47 seconds, as opposed to an average 66 seconds for men. There have been comparable differences in progress in other endurance events, such as long distance cycling and swimming.

Some argue that women will never catch up. Perhaps they are right - but almost certainly for the wrong reasons. Women's progress in sport has been retarded not by their own physiological frailty or bodily deficiences but by myths about their physical capabilities. The myths have their origins in medical discourses of the nineteenth century; but so perfectly did they suit more general beliefs about women, their position in the sexual division of labour, and their domestic duties that they were eagerly accepted as "fact" by a British society encrusted in patriarchy.

Thomas Laqueur's studies of medical texts indicate that the concept of a sharp division between male and female is a product of the past 300 years and, for 2000 years before that bodies were not visualised in terms of differences. In other words, there were people, some of whom could have children, others of whom could not; sexual difference was not a concept, so it was impossible to conceive of a distinct bifurcation of types based on sexual identity. Even physical differences that we now regard as obvious were not so obvious without a conceptual understanding of sexual differences. In some periods, a woman's clitoris was thought to be a minuscule protuberance, an underdeveloped version of the equivalent structure in men-the penis.

For most of human history, the stress was on similarities, the female body being just a "gradation" or nuance of one basic male type. Needless to say this vision complemented and bolstered a male centred world view in which, as Laqueur puts it, "man is the measure of all things, and woman does not exist as an ontologically distinct category".

The tradition of bodily similarities came under attack, particularly from anatomists who argued that sex was not restricted only to reproductive organs, but affected every part of the body. Anatomists' interest in this was fired by the idea that even the skeleton had sexual characteristics. Londa Schiebinger's medical history shows that anatomists in the nineteenth century searched for the sources of women's difference and apparent inferiority. ${ }^{2}{ }^{3}$ Depictions of the female skull were used to "prove" that women were naturally inferior to men in intellectual capacities. In the process, the concept of sexual differences was integrated into the discourse, so that, by the end of the nineteenth century, female and male bodies were understood in terms of opposites, each having different organs, functions, and even feelings.

Nelly Oudshoorn's work picks up the story by identifying how the female body became conceptualised in terms of its unique sexual essence in the 1920s and 1930s. ${ }^{4}$ In these decades, sex endocrinology created a completely new understanding of sexual differences based on 
hormones. Eventually, hormonal differences became accepted natural facts. Knowledge, on this account, was not discovered but produced: research on hormones created a different model of the sexes which was adopted universally and served to reshape our most fundamental conceptions of human nature. Women were different from men in a most profound categorical and immovable way.

So women were not only discouraged from participating in sports and exercise, but were warned against it. "Medical advice concerning exercise and physical activity came to reflect and perpetuate understandings about women's 'abiding sense of physical weakness' and the unchangeable nature of her physical inferiority," writes Patricia Vertinsky. ${ }^{5}$ Vertinsky's article "Exercise, physical capability, and the eternally wounded woman in late nineteenth century North America" explores how physicians' interpretation of biological theories of menstruation led them to discourage taxing physical exertion.

There were some schools of thought that held that the enfeebling effects of menstruation could be offset by cold baths, deep breathing, and mild exercising, such as beanbag throwing, hoops, or golf. Especially appropriate, according to Alice Tweedy, writing in Popular Science Monthly in 1892, were "homely gymnastics"-that is, housework. Other physicians prescribed rest and energy conservation. While these may sound like (if the reader will pardon the phrase) old wives' tales, they had the status of scientific fact in the period when organised sports were coming into being. Sports were intended for men only.

This did not stop women who wanted to get involved in sports, and Lenskyj ${ }^{6}$ provides examples of competitors in several sports and women's organisations that would cater for them. She also points out that sportswomen were generally seen as odd. Labelled as tomboys or hoydens, they were thought to lack "femininity" and even represent a moral degeneracy that was thought to be creeping into society.
"Although some doctors advocated exercise therapy in the early 1900s, a time when rest, not exercise, was the accepted medical treatment for virtually all diseases and injuries, they rarely made the connection between exercise therapy and women's full sporting participation," writes Lenskyj. ${ }^{6}$

For the first half of this century, women were excluded from all but a few sports. ${ }^{7}$ Against this background, the question is not why women lag so far behind men, but how they have managed to make up so much ground so quickly. It is at least possible that, if medical knowledge about women was more enlightened and women had been allowed to compete openly, that in all sports that demand skill as opposed to pure brawn - and, weight lifting apart, it is difficult to think of many exceptions - women might have been competing at levels comparable with their male counterparts. ${ }^{8}$

ELLIS CASHMORE

Staffordshire University

1 Laqueur T. Making sex: body and gender from the Greeks to Freud. Cambridge MA: Harvard University Press, 1990:2

2 Schiebinger L. Skeletons in the closet: the first illustrations of the female skeleton in eighteenth-century anatomy. In: Gallagher C, Laqueur T, eds. The making of the modern body: sexuality and society in the nineteenth century. Berkeley: University of California Press, 1987.

3 Schiebinger L. The mind has no sex: women in the origins of modern science. Cambridge MA: Harvard University Press, 1989.

4 Oudshoorn N. Beyond the natural body: an archeology of sex hormones. London: Routledge, 1994.

5 Vertinsky P. Exercise, physical capability, and the eternally wounded woman in late nineteenth century North America. Fournal of Sport History 1987;14: 8

6 Lenskyj H. Out of bounds: women, sport and sexuality. Toronto: The Women's Press, 1986:30.

7 Hargreaves J. Sporting females: critical issues in the history and sociology of women's sports. London: Routledge, 1994.

8 Birke L, Vines G. A sporting chance: the anatomy of destiny. Women's Studies International Forum 1987;10.
Cystic fibrosis (CF) was previously a disease associated with childhood death. Currently, mean survival has extended into the fourth decade of life and large numbers of patients are living good quality lives, pursuing further education, following a career pathway, forming relationships, and having a family. This increased survival is mainly due to continuous multidisciplinary care provided by paediatric and adult CF centres, which results in better nutrition and pulmonary function, the two main prognostic factors for improved survival. ${ }^{1}$ As more therapeutic options are being offered to patients with CF by their carers, it is becoming increasingly difficult for the patients to incorporate a demanding daily regimen of self care into an already busy day. Because the lives of patients with CF have become so busy, it is often necessary to tailor and sometimes omit treatment options to fit with lifestyle. Increasingly sport and exercise are being advanced as a core component of treatment for patients with CF of all ages. Where does exercise fit into the hierarchy of exclusion and inclusion? What are the medical benefits that perhaps make exercise a justifiably higher priority than for instance chest physiotherapy or inhaled antibiotics? What do the patients prefer to do if given a choice? Does exercise offer a better quality of life or perhaps even increased survival?
A large portfolio of exercise literature has already established that supervised exercise programmes enhance fitness, increase sputum clearance, and reduce breathlessness. ${ }^{2-4}$ Fitness is also associated with an improved survival. ${ }^{56}$ However, exercise should be viewed as fun as well as therapy and its role should be viewed equally from the patient's point of view as well as a clinical mandate from the multidisciplinary team. Exercise makes you feel better, and the social benefits in terms of mixing with peers are self evident. Can patients with CF participate in sporting activities to the same degree as their friends? Are there limitations or risks? What medical advice should be given to the individual patient as to risks and precautions according to disease severity? It is self evident that patients with CF participate in all sports, and their fast lane approach to life is highlighted by their attraction to some sporting activities that involve risk to life and limb.

During school years, the good health of most patients with CF resulting from good paediatric care enables them to participate in the usually compulsory school sports which include football, cricket, tennis, running, swimming, rounders, and volleyball. In adult life (over 16 years of age), patients with CF attending our clinic continue to play football, cricket, squash, and badminton, go running, belong to cycling clubs, and ski-sometimes to a very high 
standard. Our unit has included professional skiers and county badminton players. Patients with CF have also run full and half marathons. Clearly, patients with CF who are reasonably well nourished and have adequate ventilatory capacity as defined by their forced expiratory volume in one second $\left(\mathrm{FEV}_{1}\right)$ can undertake any sporting activity of their choice.

Should patients with CF be warned against specific sports? What medical precautions should be advised for other sports? The sports that carry a medical risk for patients with CF include bungee and parachute jumping, skiing, and scuba diving. Patients with CF who have portal hypertension with significant enlargement of spleen and liver should probably be advised against contact sports such as rugby, parachute, and bungee jumping. One of our patients with CF who gave up rugby because of severe portal hypertension went bungee jumping, torted his liver, which decompensated and required an urgent liver transplant. Skiing for patients with CF who are already hypoxic is ill advised, and episodes of acute right heart failure brought on by a combination of altitude and unaccustomed fierce anaerobic and aerobic exercise is well documented. ${ }^{7}$ Scuba diving is contraindicated for patients with lung disease if there is any evidence of air trapping. On ascent, the air expands, with the real risk of development of a pneumothorax. The presence of sinus disease in almost all patients with $\mathrm{CF}$ is a contraindication to diving at depth. Increasingly recognised is the occurrence of low bone density in $25 \%$ of CF adults, ${ }^{8}$ which poses a potential risk for all contact sports. Conversely, osteoporosis is associated with physical inactivity. All patients with CF should be encouraged to exercise to prevent a reduction in bone mineral density.

All patients with CF undertaking endurance sport or exercise should be well hydrated and take additional salt tablets. Sporting activity should not be undertaken during infective exacerbations.

Patients with CF prefer exercise to any other form of treatment modality. ${ }^{9}$ As pulmonary disease progresses, patients become limited in their exercise capacity with an associated decline in quality of life. It is important to provide individually designed exercise programmes for patients with CF with all grades of disease severity. Patients with good lung function can be provided with testing programmes, which will improve their aerobic and anaerobic capacity. Equally, patients with CF awaiting a transplant must remain mobile rather than bed bound. Safe exercise programmes can be designed for sick patients. If significant oxygen desaturation or severe breathlessness limit activity, then liquid oxygen can be provided in the domicilary setting. In hospital, hypoxic breathless patients awaiting transplantation can exercise gently on a treadmill with oxygen at sufficient flow to match minute ventilatory requirements. Thus quality of life and morale can be maintained for the fittest and the sickest patients with CF.
Pulmonary rehabilitation is usually directed at patients with chronic obstructive pulmonary disease to improve quality of life by reducing breathlessness and increasing mobility. If it could be proved that exercise improves survival in $\mathrm{CF}$, then it should become an essential part of care for patients with CF through childhood to adulthood. Two studies of exercise testing reported better survival in the fitter patients. ${ }^{56}$ The two factors that are most strongly correlated with survival in CF are resting pulmonary function and nutritional status; both these factors are correlated with maximal oxygen consumption. There are no long term studies of exercise assessing the effect on pulmonary function and nutritional status. One could speculate that regular exercise would maintain pulmonary function by improving sputum clearance and reduce residual volume, as has been shown in one study. ${ }^{4}$ Correspondingly, exercise improves appetite and, although weight is not increased, more fat may be converted into lean body mass. One long term exercise study of four remarkably fit patients with CF (two completing marathons) showed an increase in weight and $\mathrm{FEV}_{1}{ }^{10}$

Patients with CF increasingly are pursuing normal lives associated with increased longevity. Patient preference and some proven therapeutic gains have shown that sport and exercise have a genuine role in their lifestyle and should be encouraged. However, it is commonsense that medical guidance should always be provided for all sporting activities, and stimulating research questions as to the long term benefits of exercise programmes need to be answered.

ANTHONY KEVIN WEBB MARY ELIZABETH DODD

Manchester Adult Cystic Fibrosis Unit, North West Lung Centre, Wythenshazve Hospital, Manchester M23 9LT, United Kingdom

1 Mahadeva R, Webb K, Westerbeek RC, et al. Clinical outcome in relation to care in centres specialising in cystic fibrosis: cross sectional study. $B M \mathcal{F}$ care in centres sp

2 Orenstein DM, Franklin BA, Doershuk CF, et al. Exercise conditioning and cardiopulmonary fitness in cystic fibrosis: the effects of a 3 month supervised running program. Chest 1981;80:392-8.

3 Bilton D, Dodd M, Abbott J, et al. The benefits of exercise combined with physiotherapy in the treatment of adults with cystic fibrosis. Respir Med 1992;86:507-12.

4 O'Neill PA, Dodd M, Phillips B, et al. Regular exercise reduces breathlessness in patients with cystic fibrosis. British fournal of Diseases of the Chest 1987;81:62-9.

5 Nixon PA, Orenstein DM, Kelsey SF, et al. The prognostic value of exercise testing in patients with cystic fibrosis. $N$ Engl f Med 1992;327:1785-8.

6 Moorcroft AJ, Dodd ME, Webb AK. Exercise testing and prognosis in adult cystic fibrosis. Thorax 1997;52:291-3.

7 Speechley-Dick ME, Rimmer SJ, Hodson ME. Exacerbations of cystic fibrosis after holidays at high altitude: a cautionary tale. Respir Med 1992;86:55-6

8 Haworth CS, Selby PL, Webb AK, et al. Osteoporosis in adults with cystic fibrosis. $\mathcal{F} R$ Soc Med 1998;91:14-18.

9 Abbott J, Dodd M, Bilton D, et al. Treatment compliance in adults with cystic fibrosis. Thorax 1994;49:115-20.

10 Stranghelle JK, Skyberg D, Haanaes OC. Eight year follow up of pulmonary function and oxygen uptake during exercise in 16-year old males with cystic fibrosis. Acta Paediatr Scand 1992;81:527-31 